\title{
Hairy Mary: Natal Government Railways 2-8-2 (Tanic Tender Locomotive Havelock) \\ Woll J.A. Hattingh*
}

This locomotive was actually a Havelock tank Tender-Locomotive with the wheel arrangement of 2-8-2. It was designed in 1887 and built in the Durban workshops. It was the first locomotive to be built in South Africa. It also boasted to be the first locomotive with an eight coupled wheel but was later rebuilt as a 4-6-2.

This engine was named after Sir Arthur Havelock, the Governor of Natal. She was accepted into service in 1888 and was fitted with a Stephenson valve gear and her tractive force at $75 \%$ was 14473 pounds.

All sizes and capacities are in Imperial measures.
She had a boiler pressure of 140 pounds per square inch and the water capacity on the side tanks was 880 gallons and in the tender was 900 gallons. The coal capacity was $3 \frac{1}{2}$ tons.

The approximate weight of the engine was 38 tons and that of the tender was 12 tons (working weight).

Her leading wheels and also the trailing wheels were fitted with Webb type radial axil bases. There were also two sand boxes on the boiler. She had both the Salter and Ramsbottom safety valves.

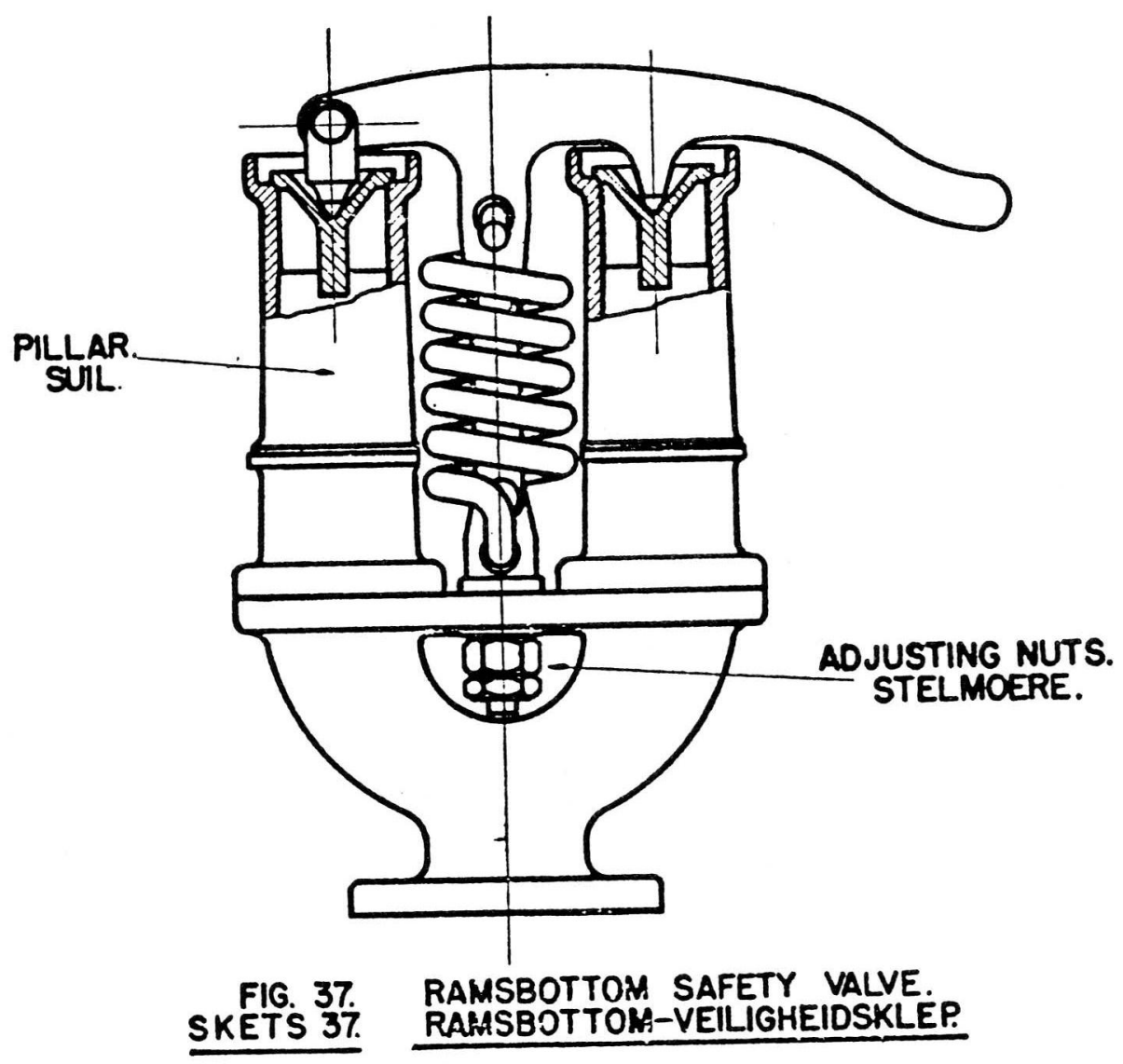

Sketch of Ramsbottom Safety Valve. 
This locomotive saw active service during the Boer War when she was used to pull armoured trains. She was not given armour plating as a great number of operational locomotives but was covered with thick Hemp rope.
The rope was draped over the entire locomotive from front to back and because the rope was "hairy" she was given the name of "Hairy Mary" by the soldiers. She carried the number of 48 .

This engine was scrapped in 1905.

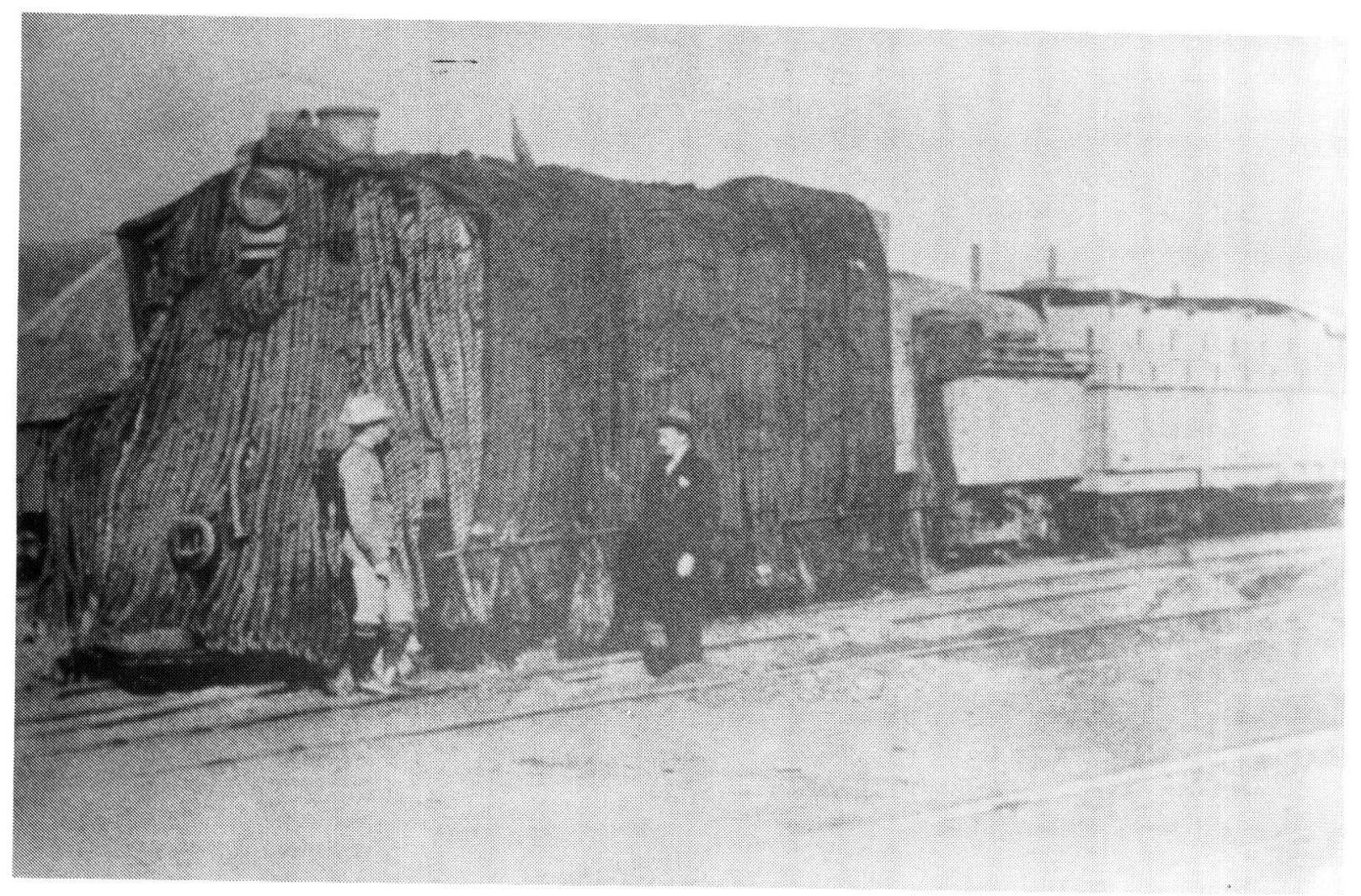

Photograph of "Hairy Mary"

WOIl J.A. Hattingh, Diploma (Printers) attested in the SADF on 1 February 1978 and is employed as a photolithographer.

\section{Reference Material}

1. Steam locomotives of the South African Railways vol I, by D. Holland. 2. The locomotive in Southern Africa by T.J. Espitalier \& W.A.J. Day
(January 1944). 